\title{
INFLUENCE OF SURFACE RESIN COATING ON BIO-COMPATIBILITY AND ATTACHING ABILITY OF HUMAN GINGIVAL CELLS TO THE GLASS-IONOMER RESTORATIVE MATERIAL
}

\author{
Mona Denewar", Khalid M. Abdelaziz ** and Mahitabe Elgamily*
}

\begin{abstract}
Background and objective. Glass-Ionomer (G.I.) restoratives are used to manage cervical tooth defects; however certain chemicals could leach out of the material and affect the adjacent gingival tissue. Therefore, this study aimed to assess the viability and attachment of human gingival epithelial cells (HGECs) on both resin-coated and uncoated Equia fil G.I. restorative materials.
\end{abstract}

Materials and Methods. Two groups of G.I. disc specimens ( $\mathrm{n}=34$ each) were constructed from Equia fil G.I. restorative by mixing the content of G.I. capsules, then injection into silicone molds, left for setting before cutting the excess. Surfaces of group I specimens were coated with the accompanied protective Equia resin, while those in group II were left uncoated. HGECs were isolated and incubated with the constructed specimens. The cell viability was then assessed using both Methyl Tetrazolium (MTT) and Trypan blue dye exclusion (TBDE) assays. The micromorphology and the attaching ability of the isolated cells to specimens' surfaces were assessed using SEM. The surface roughness was measured and the chemical analysis of G.I. surfaces was also analyzed by energy disperse $\mathrm{x}$-ray.

Results. Reduction in HGECs viability was noticed in contact with G.I. of both test groups. However, HGECs showed better viability and attaching ability to the resin-coated G.I. surface than were in presence of uncoated restorative.

Conclusion. Resin Coating preserves the cell viability and improves the attachment of HGECs on Equia fil G.I restorative surfaces these findings, therefore, offers sound evidence to select such material in treating sub-gingival cervical tooth defects.

\section{INTRODUCTION}

The management of both carious and noncarious cervical lesions in addition to some cases of accidental supra-crystal root perforations is a challenging situation that requires special attention. Many natural and synthetic materials are used to replace and repair human soft and hard dental tissues. These materials normally express either direct or

* Lecturer of Oral Biology, Faculty of Dentistry, Mansoura University

** Department of Restorative Dental Sciences, College of Dentistry, King Khalid University, Abha, Saudi Arabia 
indirect interactions with the nearby structures. (1) Some of the commonly used restorative/repair materials could leach out certain chemicals that could, in some way, affect the in-contact gingival tissue cells. Therefore, the evaluation of these materials usually covers their biocompatibility as well as their chemical, physical and mechanical characteristics. The assessment of biocompatibility should determine the impact of the studied material on cell viability/cytotoxicity that seems to be a complicated process with various mechanisms those usually causes functional and structural alterations in tissue cells. ${ }^{(2)}$

The gingival epithelium normally generates a barrier that diminishes the bacterial invasion to the underlying tissue. Epithelial cells are generally connected by desmosomes, tight junctions, gap junctions and adherence junctions. The existence of the multi-protein cell junction complexes between the epithelial cells is essential for maintaining the functional and physical integrities of the tissues. ${ }^{(3)}$ The attachment and the interaction of gingival cells to dental restoratives are important for clinically successful dental restorations. Manufacturing of dental restoratives usually claim the ability of these materials to offer the requested responses of the in-contact tissue cells. Accordingly, both the composition of the restorative material and its surface characteristics are essential for successful healing and attachment of the affected gingival tissues. ${ }^{(4)}$

Glass-ionomer cements (G.I.) have been presented to adhesive dentistry many years ago.
Although it is frequently classified as a cement material, it is commonly used as esthetic and intermediate restorative material. ${ }^{(5)}$ In response to its mechanical, unique bonding and fluoride release characteristics, G.I. have been nominated the restorative materials of choice in treating cervical tooth lesions. ${ }^{(6)}$ However, the biological biocompatibility studies of G.I. were not conclusive as some reports suggest that the material is cytotoxic while other reports claimed the contrary. ${ }^{(7)}$ This conflict has been referred to the nature of different additives in the compositional formulae of the tested G.I. materials. Therefore, searching for a safe and effective cervical restorative/repair material that ensures reattachment of the overlaying gingival tissue seems to be an important issue.

A new generation of G.I. restorative system (EQUIA $^{\text {Tu }}$, GC Corp, Tokyo, Japan) has recently been introduced to the dental market. This system combines a self-adhesive, chemically-cured, highlyfilled Equia fil G.I. restorative and a self-adhesive, hydrophilic, highly-filled, light-cured protective Equia Coat (Table 1). The EQUIA ${ }^{\mathrm{TN}}$ system offers a great substitute for long-term routine fillings and its manufacturer claims that the material has increased fracture toughness, flexural strength, and flexural fatigue resistance in addition to the low moisture sensitivity which are required in cervical restorations. ${ }^{(5,8)}$

Therefore, the aim of this study is to explore the cyto-biocompatibility of the Equia fil G.I. in presence and absence of the Equia coat. Assessing

TABLE (1) Description of Equia Fil Restorative System

\begin{tabular}{lll}
\hline Material & Manufacture & Chemical composition \\
\hline Equia fil & GC Corporation & Powder: $95 \%$ strontium fluoroalumino-silicate glass, 5\% polyacrylic acid \\
& Tokyo, Japan & Liquid: $40 \%$ aqueous polyacrylic acid \\
\hline Equia coat & GC Corporation & $50 \%$ Methyl methacrylate, $0.09 \%$ camphorquinone \\
& Tokyo, Japan & \\
\hline
\end{tabular}


the viability of human gingival epithelial cells and their adhesion on surfaces of the nominated materials could reveal and evidence for possible clinical application in repairing and restoring all kinds of sub-gingival cervical lesions. The hypothesis of this work was that the resin-coated Equia fil G.I. would offer better viability and attachment of HGECs than the uncoated Equia fil G.I.

\section{MATERIAL AND METHODS}

The isolation process and the cell viability tests were performed in Mansoura Nile Research Center while the electron microscope investigation was performed in the Electron Microscope Unite Mansoura University.

\section{Isolation of human gingival epithelial cells (HGECs)}

Specimens of healthy human gingival tissues were used to isolate the needed human gingival epithelial cells (HGECs). These specimens were collected following the approval of the Ethical Authorities at The Faculty of Dentistry, Mansoura University, Egypt and the legal agreements of 3 healthy donors undergoing surgical removal of their wisdom teeth. With minor modification to the protocol followed by Fujita et al. ${ }^{(9)}$, on sixty mm plastic tissue culture plates coated with type I collagen (Sumitomo Bakelite, Tokyo, Japan) and before incubation in 5\% $\mathrm{CO}_{2} / 95 \%$ air at $37 \pm 1^{\circ} \mathrm{C}$, the isolated HGECs were seeded in Humedia-KB2 (KURABO, Osaka, Japan) containing $10 \mathrm{mg} / \mathrm{ml}$ insulin, $5 \mathrm{mg} / \mathrm{ml}$ transferrin, $10 \mathrm{mM}$ 2-mercaptoethanol, $10 \mathrm{mM}$ 2-aminoethanol, $10 \mathrm{nM}$ sodium selenite, $50 \mathrm{mg} / \mathrm{ml}$ bovine pituitary extract, 100 units $/ \mathrm{ml}$ penicillin, and $100 \mathrm{mg} / \mathrm{ml}$ streptomycin.

The cultured cell proliferation and contamination were daily tested under inverted light microscopy. Estimation of cell confluence was done qualitatively using inverted microscope; by observing the space occupied by the cells and their colonies in the flask. Quantitative assessment was done by cell counting using 0.4 hemocytometer of depth $0.1 \mathrm{~mm}$, and ordinary microscope to count the number of viable cells. Then, applying in this formula;

Number of viable cells/ flask $=$ average cell count per square $\mathrm{x}(10)^{4} \mathrm{x}$ dilution factor

Once the seeded cells reached the confluence, they were detached using $0.25 \%$ trypsin in ethylene diamine tetra acetate (EDTA), diluted with PBS; $1: 1$; Invitrogen/Gibco), and centrifuged before their resuspension and counting (Casy Modell TT, Schärfe System, Germany). Afterwards sub-cultivation of cells was done in the culture dishes in presence of different restorative material specimens. The cultured HGECs at the fourth passage were used in this study.

\section{Preparation of G.I. specimens}

A total of 68 disc specimens, $9 \mathrm{~mm}$ in diameter and $2 \mathrm{~mm}$ thick were constructed from Equia fil G.I. (GC Corp, Tokyo, Japan). The material capsules were shaken up to loosen the powder contents and activated by hand plunger immediately before mixing their contents using an amalgamator (Softly, Acteon group, Italy) for 10s. The triturated capsules were removed, and the mixed material was injected by the aid of metal applicator into a silicone mold (Express Penta Putty, 3M ESPE, Seefeld, Germany) held on a plastic strip supported with a glass plate. To flatten the surfaces of the constructed specimens, another plastic strip and a second glass plate were pressed onto the top surface of the mold using a standard weight of $5 \mathrm{~kg}$. The injected material was left for $2.5 \mathrm{~min}$ to initially set before cutting the excess using a sharp instrument (Scalpel blades, Bard-Parker no.15).

After releasing the constructed 68 specimens out of their molds, they were divided into two groups $(n=34)$ each. In group I (coated) the surfaces of the specimens were brushed first with a double layer of the Equia resin coat, each was cured for 20s with LED light (Radii Plus, High power $1500 \mathrm{~mW} / \mathrm{cm}^{2}$, 
SDI, Australia) then they were incubation for $24 \mathrm{~h}$ at $37 \pm 1^{\circ} \mathrm{C}$ in $100 \%$ relative humidity to reach their full setting. The coated surfaces after then were polished using 1400 grits abrasive paper discs (Soflex, 3M ESPE, USA), washed up, dried and recoated with the light cured Equia resin. Group II specimens (uncoated) were incubated in the same ambient conditions regarding temperature and humidity to reach their final setting. The un- coated surfaces after then were polished using the same abrasive paper discs before their washing up and drying.

\section{Testing the Cell viability}

Both methyl tetrazolium (MTT) and trypan blue dye exclusion (TBDE) assays were used to assess the viability of the G.I. These tests were conducted on 20 specimens out of each group of the restorative material. The isolated HGECs were implanted in 96-well plates with GI specimens of each group, the cell concentration was $2 \times 10^{5}$ cells/well. Wells containing cell suspension with no material's specimen in served as control. All culture plates were then incubated in $5 \% \mathrm{CO} 2$ at $37 \pm 1{ }^{\circ} \mathrm{C}, 95 \%$ humidity for 24 and $72 \mathrm{~h}$.

\section{MTT assay}

The MTT test was performed using Vybrant MTT Cell Proliferation Assay Kit (V-13154)..(10) This assay measures the ability of cells to reduce the MTT dye into an insoluble purple formazan by succinate dehydrogenase enzyme present within the mitochondria. Because the reaction requires functional mitochondria, it is considered effective in evaluating the metabolic activity of living cells.

The MTT stock solution was prepared by sonication of $5 \mathrm{mg} / \mathrm{mL}$ MTT in PBS and stored at $-20^{\circ} \mathrm{C}$. After cell incubation for 24 and $72 \mathrm{~h}$, the media was aspirated carefully and replaced with 100 $\mu \mathrm{L}$ of fresh culture medium. Only $10 \mu \mathrm{L}$ of MTT solution was added into each well and a negative control was prepared by the addition of $10 \mu \mathrm{L}$ MTT to $100 \mu \mathrm{L}$ medium alone. The plate was incubated at $37^{\circ} \mathrm{C}$ for 4 hours. After incubation, $100 \mu \mathrm{L}$ of MTT solvent [Sodium Dodecyl Sulfate (SDS) in HCL] was added into each well. Wrapping the plate with foil and shaking on an orbital shaker for $15 \mathrm{~min}$ were then performed.

Occasionally, pipetting of the liquid may be required to fully dissolve the MTT formazan. The dye absorbance was read within 1 hour in a micro-plate reader (Biotek instrument, Highland Park, Winooski,Vermont, USA) at $\mathrm{OD}=570 \mathrm{~nm}$. The absorbance in wells of each test group was averaged as five measurements at each time point and calculated against the control.

\section{Trypan blue dye exclusion assay (TBDE)}

The cell viability was assessed by trypan blue dye exclusion test because the Trypan blue (SigmaAldrich, Taufkirchen, Germany) is a vital dye and its reactivity is due to negatively-charged chromopore that interact only with cells having damaged membrane. ${ }^{(11)}$ After incubation for 24 and $72 \mathrm{~h}$, cells were exposed to $0.4 \%$ trypan blue and cell count was done cell $/ \mathrm{mm}$ in a haemocytometer (Bright Line Hemacytometer, Sigma-Aldrich).

The adherent cells were washed with PBS and trypsinized (Trypsin-EDTA Solution, SigmaAldrich) to dissociate the cell clusters from the culture plates and specimens then re-suspended in a fresh minimal essential medium (MEM) (SigmaAldrich). The cell suspension was mixed by pipetting several times to get uniform single cell suspension, then $20 \mu \mathrm{l}$ of $0.4 \%$ trypan blue dye was added to 20 $\mu l$ of the cell suspension. The well-mixed content was then incubated for $3 \mathrm{~min}$ at room temperature to allow dead cells to take up the dye and the viable cells to pump out the stain by efflux mechanism. The cell counting process started in fewer than 5 min after staining. The cover slip was placed and 
$10 \mu \mathrm{l}$ of the prepared trypan blue-cell suspension was transferred to haemocytometer before its placement on the stage of an inverted microscope. Both the focus and the power of the microscope were then adjusted until the field was filled with a single calculating square. The number of cells was counted per $\mathrm{ml}$ and the percent cell viability (\%) was calculated using the following formula ${ }^{(12,13)}$;

$\%$ Cell Viability $=($ Viable cell count $/$ Total cell count) $\times 100$

\section{Scanning electron microscopy (SEM)}

SEM examination was conducted on G.I. specimens of both groups (9 specimens out of each group). After incubation with HGECs for $3 \mathrm{~h}, 24 \mathrm{~h}$ and $72 \mathrm{~h}$ at $37 \pm 1{ }^{\circ} \mathrm{C}$ under $100 \%$ relative humidity, the incubating medium was removed and meticulous washing ( 3 times for $5 \mathrm{~min}$ ) of all specimens with TBST took place at room temperature. The glutaraldehyde was then used to finalize the cell fixation process. To dehydrate the cells, 90\% ethanol; 96\% isopropanol and 100\% isopropanol were respectively used for $20 \mathrm{~min}$. Dried specimens were then coated with $10 \mathrm{~nm}$ gold plasma and observed with SEM (TESCAN VEGA3, Shanghai, China) at X2000 original magnification to assess the micromorphology and the attachment of HGECs. The chemical analysis of G.I. surfaces was also investigated by energy disperse $\mathrm{x}$-ray analysis (EDX).

\section{Measuring the surface roughness}

The roughness average ( $\mathrm{Ra}$ ) of 10 specimen's surfaces was assessed according to the ISO specification \# 4287-1997 using 2-D profilometer (Surftest SJ210, Mitutoyo Corp., Kawasaki, Japan). Top surfaces of five specimens out of each group were subjected to $2.5 \mathrm{~mm}$ long stylus trips in five different directions starting from the center of the specimen's surface at a moving speed of $0.5 \mathrm{~mm} / \mathrm{s}$.
The average $\mathrm{Ra}$ for each specimen was then calculated in $\mu \mathrm{m}$.

\section{Statistical analysis}

The collective cytotoxicity surface roughness data were analyzed using Version 26 of the Statistical Package for Social Science software (SPSS Inc., Chicago, IL). Both ANOVA and Tukey's tests at $\alpha=0.05$ were used to assess the differences in the collected quantitative parametric data and determine the significance of the detected differences between test subgroups. Testing the correlation between surface roughness and the attaching ability of HGECs was also considered.

\section{RESULTS}

\section{HGECs morphology}

In HGECs culture, normal cell colonies grew slowly and several days were needed for the number of cells to duplicate. The culture constituted large flat cells and small polygonal cells after 8 days. After 8,10 and 12 days colonies formation was observed progressively, the cells were respectively about 60,80 and $100 \%$ confluence (Fig. 1).

\section{HGECs viability}

The mean viabilities of HGECs subjected to the tested restorative materials at the two exposure times in addition to the standard deviations are represented in Table 2. The MTT assay demonstrated higher cell viability (\%) at 24 and 72 hours in presence of the resin-coated Equia G.I. restorative than was in presence of the uncoated material $(\mathrm{P}<0.001)$. On the other hand, the two materials represented significant reduction in cell viability in comparison to the control group through different time intervals $(\mathrm{P}<0.05)$. The same results were detected in TBDE assay that showed higher cell viability (\%) with the resin-coated Equia G.I. than that detected with the uncoated G.I. restorative (Table 3). 


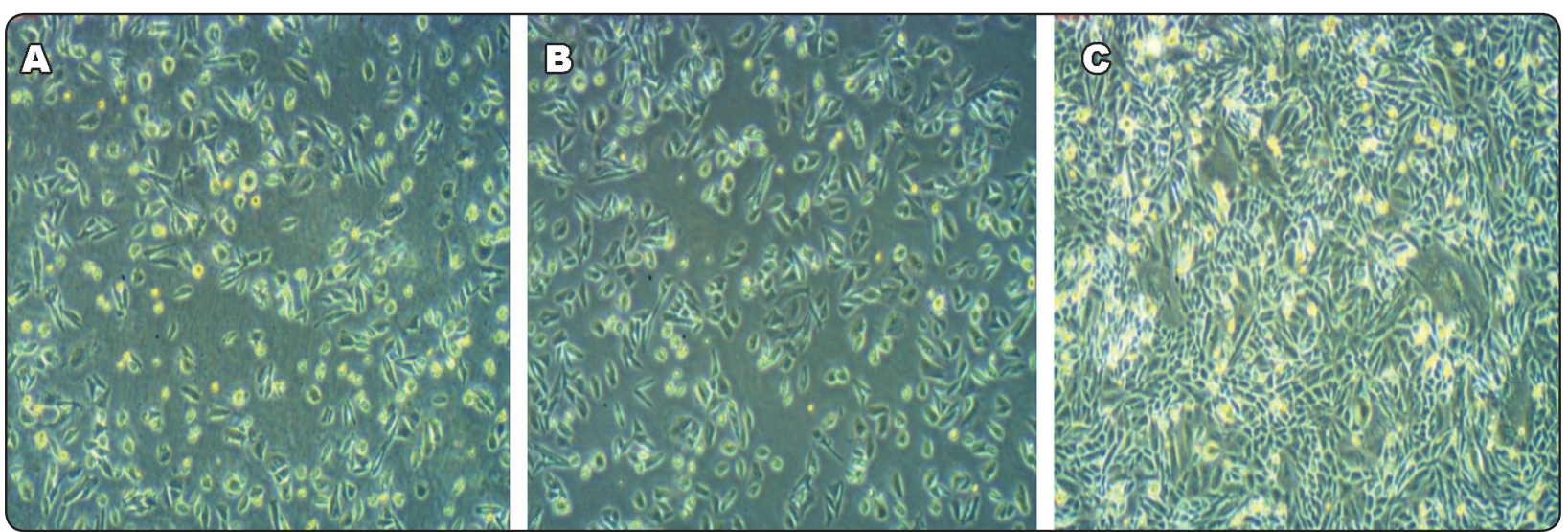

Fig. (1) Phase-contrast images showing morphological changes of cultured normal human gingival epithelium cells: A) After 8 days; B) After10 days and C) After 12 days of culture.

TABLE (2) HGECs viability as evaluated by MTT assay

\begin{tabular}{|c|c|c|c|}
\hline \multirow{2}{*}{ Time } & \multicolumn{1}{c}{$\begin{array}{c}\text { Control } \\
\text { group }\end{array}$} & \multicolumn{1}{c}{$\begin{array}{c}\text { Equia GI with } \\
\text { coat }\end{array}$} & $\begin{array}{c}\text { Equia GI } \\
\text { without coat }\end{array}$ \\
\hline $24 \mathrm{~h}$ & $3.898 \pm .12$ & $2.717 \pm .050^{\mathrm{a}}$ & $1.359 \pm .087^{\mathrm{bc}}$ \\
\hline $72 \mathrm{~h}$ & $4.171 \pm .09$ & $2.802 \pm .128^{\mathrm{a}}$ & $1.605 \pm .134^{\mathrm{bc} / *}$ \\
\hline
\end{tabular}

*= Significance between 24 and $72 h$ within each group

$a=$ Significance between Control \& resin-coated G.I. restorative test groups

$b=$ Significance between Control and uncoated G.I. restorative test groups

$c=$ Significance between resin-coated and uncoated G.I. restoratives

TABLE (3) HGECs viability (cell/ $\mathrm{ml}$ ) as evaluated by TBDE assay

\begin{tabular}{|c|c|c|}
\hline Time & \multicolumn{1}{|c|}{ Resin-coated Equia G.I. } & Uncoated Equia G.I. \\
\hline $24 \mathrm{~h}$ & $67.23 \pm 4.02$ & $34.92 \pm 2.98^{\#}$ \\
\hline $72 \mathrm{~h}$ & $69.76 \pm 2.14$ & $38.48 \pm 3.06^{\# / *}$ \\
\hline
\end{tabular}

* = Significance between 24 and 72 within each group

\# = Significance between resin-coated and uncoated

Equia G.I. restoatives within each time interval

\section{Cells attachment}

SEM images (X5000) of HGECs grown on resin-coated and uncoated G.I. surfaces after 3, 24 and $72 \mathrm{~h}$ of culture are shown in (Fig. 2). At $3 \mathrm{~h}$, SEMs revealed individual rounded discoid HGECS exhibiting roughly smooth surface with cytoplasmic extensions that projected from the cells to the surrounding coated G.I. surface. After $24 \mathrm{~h}$ of cells culture, HGECs on the coated G.I. surface appeared roughly round with irregular surface and blebs. They were spreading out with formation of microvilli and filopodia. As the time progressed, HGECs spreading was evident with intimate contact to the substrate by means of lamellipodia. After 72 hours of culture, magnification (X5000) clearly showed individual HGECs spreading and attachment to the coated G.I. surfaces via filopodia extensions. In case of uncoated G.I. specimens, HGECs attachment was limited with only few rounded cells appearing on the surface of the uncoated G.I. surface which had ruffles on their surfaces. In general, SEM analysis revealed better cell adhesion and spreading on the resin-coated G.I. surfaces in comparison to that on uncoated G.I. surfaces. 


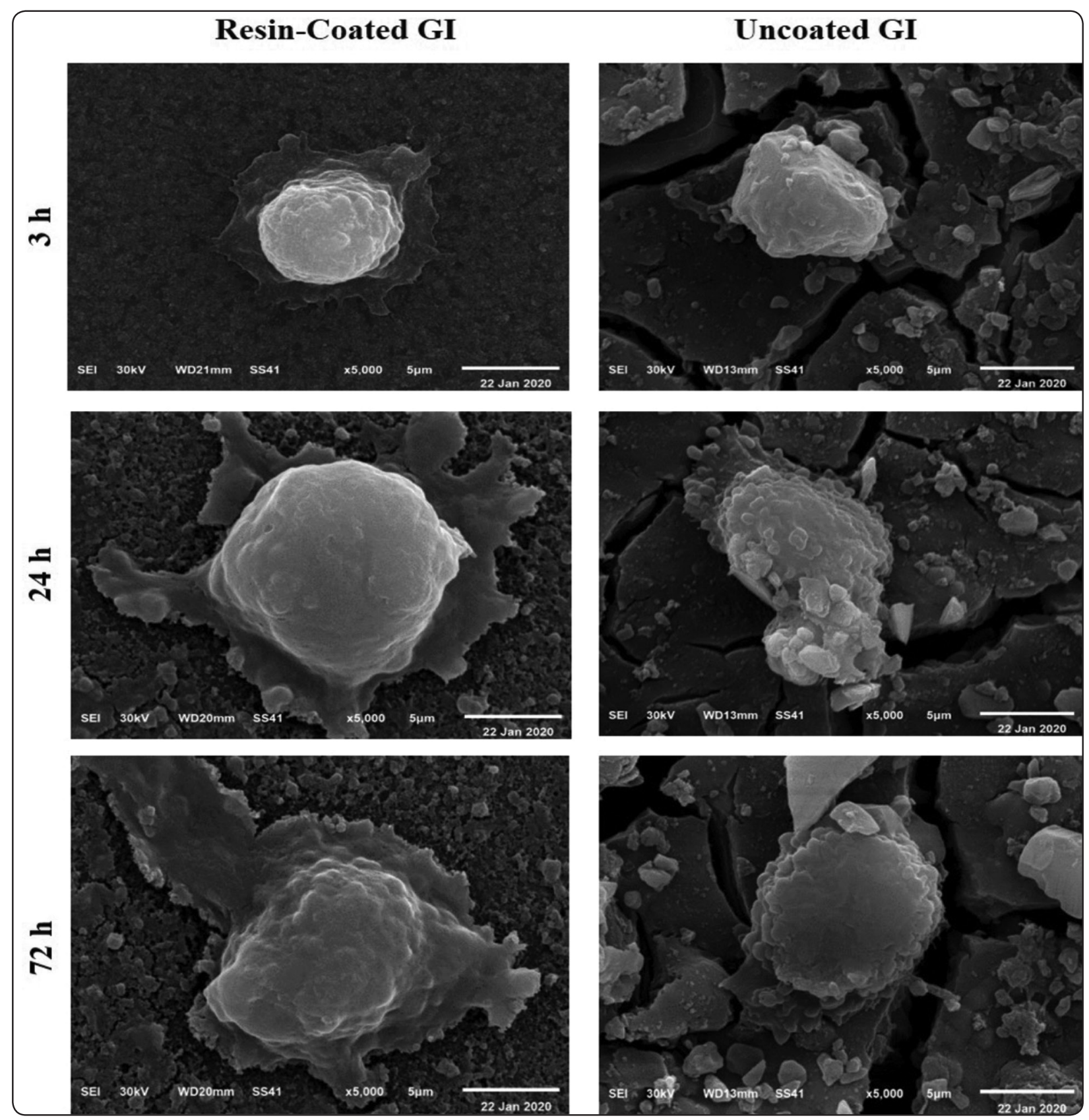

Fig. (2) SEM at (X5000) of HGECS grown on resin-coated and uncoated G.I. after 3, 24 and $72 \mathrm{~h}$ of culture. 


\section{SEM and EDX of G.I. specimens}

SEM images (X 5000) of different GI specimens (Fig. 3) revealed relatively smooth surface of the resin-coated G.I. specimens, while the uncoated G.I. surfaces were characterized by the presence of surface irregularities and cracks. The EDX spectra of the G.I. discs confirm the presence of $\mathrm{Al}, \mathrm{Sr}$, $\mathrm{Na}$ and $\mathrm{F}$ ions in the set of uncoated specimens, although a considerable reduction in $\mathrm{Sr}, \mathrm{Si}$ and $\mathrm{Na}$ ion concentrations was evident in presence of resin coat.

\section{Surface roughness of G.I. specimens}

The resin-coated G.I. specimens exhibited lower surface roughness in comparison to the uncoated specimens $(\mathrm{P}<0.001)$ (Fig. 3 and Table 4). This result was statistically correlated $(\mathrm{P}>0.5)$ with the SEM findings and the HGECs attachment behavior.

TABLE (4) Mean roughness average $(\mu \mathrm{m})$ of G.I. specimens in different test groups

\begin{tabular}{ccc}
\hline \multirow{2}{*}{$\begin{array}{c}\text { Surface } \\
\text { roughness }\end{array}$} & $\begin{array}{c}\text { Resin-coated } \\
\text { surfaces }\end{array}$ & $\begin{array}{c}\text { Uncoated G.I. } \\
\text { surfaces }\end{array}$ \\
\cline { 2 - 3 } & $0.315 \pm 0.053$ & $1.230 \pm 0.231^{*}$ \\
\hline
\end{tabular}

* = Significant difference between groups $(P<0.001)$
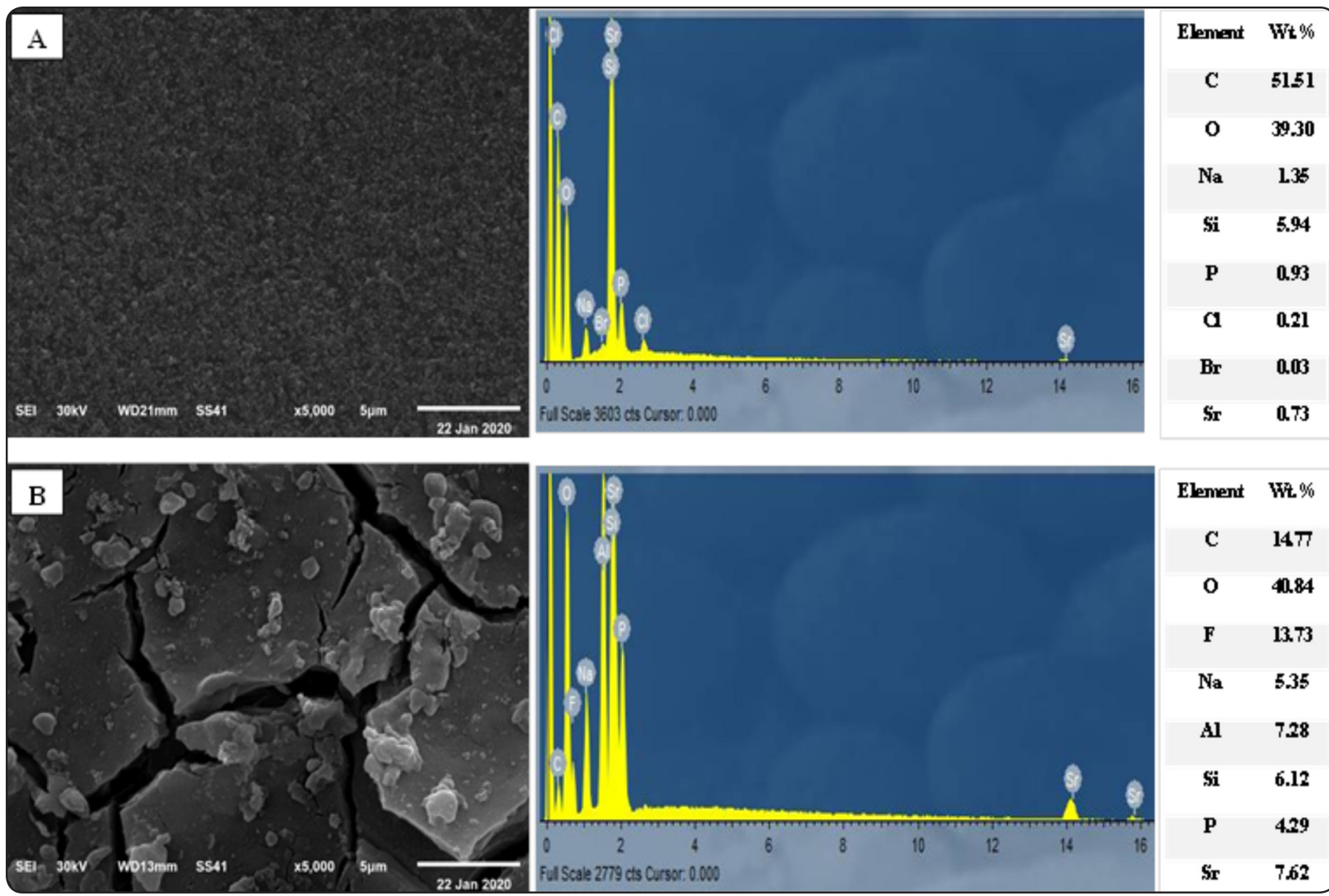

Fig. (3) Surface morphology and the chemical analysis of the resin-coated (A) and uncoated (B) G.I. specimens: SEM images (Left); EDX spectra (Middle) and tables of the detected elements (Right). 


\section{DISCUSSION}

The growing use of G.I. as a restorative material was not only limited to managing and restoring cervical tooth defects of permanent teeth but also in treating most of cases in restorative pediatric dentistry, mandate the assessment of their biological effects on the surrounding oral tissue cells. In spite of the numerous applications of G.I. in dentistry, there is an evidence of their cytotoxicity to different human cells such as primary human gingival fibroblasts ${ }^{(14)}$, cell of human periodontal ligament ${ }^{(15)}$ and osteoblast cells ${ }^{(16)}$. On the other hand, the HGECs usually represent an excellent model for studying the biocompatibility of dental materials and they were selected in the current study to test the cytotoxicity of both resin-coated and uncoated G.I. restoratives. The availability of HGECs in the oral cavity, their greater reproducibility in tissue cultures and the documented sensitivity to drugs, toxins and chemical agents were also considered at the time of selection. ${ }^{(17)}$

The Cell culturing methods seem suitable for evaluating the basic biological properties of dental materials especially when these methods are standardized and reproducible. ${ }^{(18)}$ Furthermore, the in vitro experiments have the advantage of easy-controlling the experimental variables, which is often a problem for in vivo experiments. ${ }^{(19)}$ Accordingly, The MTT assay is considered one of the standard method to evaluate the biocompatibility of any material. ${ }^{(20)}$

In this study, both MTT and TBDE assays were used to evaluate the viability of HGECs in contact with both resin-coated and uncoated Equia fil G.I. restoratives. The recorded results of these tests indicated higher cell viability (lower cytotoxicity) and higher metabolic activity of the cells cultured in presence of the resin-coated G.I. in comparison to that noticed in presence of the uncoated material at different testing time intervals. These findings were undoubtedly related to the materials' composition as
Szep et al. referred the cytotoxicity to the capacity of substance to damage tissue cells. Therefore, the biocompatibility is surely affected by material's chemical composition as well as the rate of ion released out of the material. ${ }^{(21)}$ Although Kanjevac et $a l .{ }^{(22)}$ denied the responsibilities of the leached ions for the detected cytotoxicity of the tested G.I. materials, the earlier postulation could explain the higher cytotoxicity of the uncoated G.I. as the material is known to exhibit higher solubility and leach more ions during the first $24 \mathrm{~h}$ of its setting in normal oral environment. ${ }^{(23)}$ The same first postulation was confirmed by the results of EDX that revealed a clear link between the types and amounts of chemicals released out of the G.I. restoratives and their biological properties. The increased amounts of the released Al, Sr and F ions out of the uncoated Equia G.I. (Fig. 3) may explain its higher cytotoxicity when compared with the resin-coated material. This observation has been supported by both Stanislawski et al. ${ }^{(24)}$ and Sidhu and Schmalz ${ }^{(25)}$ who confirmed the release of various ions out of the G.I. materials and their possible cytotoxic effect.

Moreover, Soheili et $a l .^{(26)}$ related the cytotoxicity of conventional G.I. to the presence of small aluminum particles which can trigger the oxidative stress in cultured cells by reduction of glutathione, production of reactive oxygen species. Other molecular mechanisms, in addition, were suggested by Marcia et al. ${ }^{(27)}$ to cause apoptosis of the cultured cells. Another in vitro study done by Chang and Chou ${ }^{(28)}$ demonstrated that fluoride ions may contribute to cytotoxic effects on the cultured human dental pulp cells by preventing cell growth, mitochondrial activity, proliferation, and protein synthesis. Fluoride can also induce programmed cell death through mitochondrial/caspase-9/caspase3-dependent pathway as reported by Theiszova et $a l .^{(29)}$ de Mendonça et $a l .^{(30)}$ also reported that the release of high concentrations of $\mathrm{F}$ ion from G.I. in wet environment may modify the cell metabolism 
or affect the DNA synthesis. Rodriguez and Ferrara (31) added that cells underwent apoptosis showed pattern of ionic alterations followed by decrease in the intracellular ATP.

On the other hand, López-García et al. ${ }^{(20)}$ proved that several components such as photoinitiators, monomers or fillers may also be related to the cytotoxicity of G.I. In addition, the uncured monomers are easily released and could be incorporated into the double lipid layer of the cell membrane causing its solubility. ${ }^{(27)}$ These explanations probably are the reasons for the significant decrease in cell viability in the early hours after setting of the resin-coated Equia G.I. when compared to the control (Cultured cells with no restorative material in contact). This could also explain the detected difference in the number of viable cells exposed to resin-coated G.I. at the different testing time intervals (Table 2 and 3).

Normally, soft tissue regeneration for further esthetics and prevention of gingival inflammation may require an increased attachment and growth of HGECs on the existing cervical and sometimes subgingival tooth restorations. Generally, the G.I. exhibits low cytocompatibility in their freshly set state as noticed in this study; however this situation decreases substantially throughout the time. ${ }^{(20)}$ In the current study, a favorable attachment and the ability to spread of HGECs was evident on the surfaces of the resin-coated Equia G.I., while a significant reduction in cell density and ability to spread was detected on the surfaces of uncoated restorative material. These observations were coordinate with the recorded viability/cytotoxicity results in both test groups. The HGECs adhesions on the G.I. surfaces were obviously associated with and statistically correlated to the degree of materials' surface roughness. Resin-coated G.I. surfaces logically exhibited lower Ra values in comparison to the uncoated surfaces (Table 4).
This finding could be explained depending on the documented solubility of the uncoated material in different wet environment. The solubility rate was found to increase during the first $24 \mathrm{~h}$ after mixing due to incomplete maturation of the material's gel matrix which makes the material so sensitive to moisture and wet environment and easily leach their free ion contents. ${ }^{(5,23)}$ These facts could significantly contribute in explaining the recorded results of cytotoxicity and cell attachment.

In spite of the recorded outcomes of this in vitro study, one should consider that absence of simulation of the in vivo conditions and the difficulties in extrapolating the data to the clinical level are the main limitations of cell culture toxicity tests. Furthermore and due to the lack of defense mechanisms, cells may show less in vitro tolerance to the in vivo biocompatible materials. ${ }^{(20)}$ Therefore, additional studies using increasing incubation times and different concentrations of the leached ions are recommended to evaluate cytotoxicity of these restorative materials.

\section{CONCLUSION}

Within the limitation of the current study, the following conclusions could be drawn;

1. Both resin-coated and uncoated G.I. restoratives demonstrate different adverse effect levels on the HGECs as they affect the cell viability but with different degree.

2. Higher HGECs viability and attachment are expected in contact with the resin-coated G.I. restorative

\section{RECOMMENDATION}

The resin-coated G.I. restorative, therefore, could be nominated to treat sub-gingival cervical tooth defects. 


\section{REFERENCES}

1. Grażyna Marczuk-Kolada , Elżbieta Łuczaj-Cepowicz, Małgorzata Pawińska, Adam Hołownia . Evaluation of the Cytotoxicity of Selected Conventional Glass Ionomer Cements on Human Gingival Fibroblasts. Adv Clin Exp Med. 2017; 26(7):1041-1045.

2. Murray PE, García Godoy C, García Godoy F. How is the biocompatibilty of dental biomaterials evaluated? Med Oral Patol Oral Cir Bucal. 2007;12 (3):E258-66.

3. Miyagawa T, Fujita T, Yumoto H, Yoshimoto T, Kajiya M, Ouhara K, Matsuda S, Shiba H, Matsuo T, Kurihara $\mathrm{H}$. Azithromycin recovers reductions in barrier function in human gingival epithelial cells stimulated with tumor necrosis factor- $\alpha$. Arch Oral Biol. 2016;62:64-9.

4. Gupta A, Dhanraj M, Sivagami G. Status of surface treatment in endosseous implant: a literary overview. Indian J Dent Res. 2010 ;21(3):433-8.

5. Dalia Mohamed Abdel Hamid, Gouda Mohamed Mahmoud, Fatma M.El-Sharkawy, Eman AlyAbou Aufd. Effect of surface protection, staining beverages and aging on the color stability and hardness of recently introduced uncoated glass ionomer restorative material. Future Dental Journal. 2018; 4 (2): 288-296.

6. Francisconi LF, Scaffa PM, de Barros VR, Coutinho M, Francisconi PA. Glass ionomer cements and their role in the restoration of non-carious cervical lesions. J Appl Oral Sci. 2009; 17(5):364-9.

7. Tamilselvam S, Divyanand MJ, Neelakantan P. Biocompatibility of a conventional glass ionomer, ceramic reinforced glass ionomer, giomer and resin composite to fibroblasts: in vitro study. J Clin Pediatr Dent. 2013; 37(4):403-6.

8. Vaid DS, Shah NC, Bilgi PS. One year comparative clinical evaluation of EQUIA with resin-modified glass ionomer and a nanohybrid composite in noncarious cervical lesions. J Conserv Dent. 2015; 18(6):449-52 .

9. Fujita T, Yoshimoto T, Matsuda S, Kajiya M, Kittaka M, Imai H, Iwata T, Uchida Y, Shiba H, Kurihara H. Interleukin-8 induces DNA synthesis, migration and downregulation of cleaved caspase- 3 in cultured human gingival epithelial cells. J Periodontal Res. 2015; 50(4):479-85.

10. Fotakis G, Timbrell JA. In vitro cytotoxicity assays: comparison of LDH, neutral red, MTT and protein assay in hepatoma cell lines following exposure to cadmium chloride. Toxicol Lett. 2006 5; 160(2):171-7.
11. Huynh NC, Le SH, Doan VN, Ngo LTQ, Tran HLB. Simplified conditions for storing and cryopreservation of dental pulp stem cells. Arch Oral Biol. 2017; 84:74-81.

12. Mai Thi-Hoang Nguyen, Khanh Loan Ly, Thoai Quoc Kieu ,Hiep Thi Nguyen, Nam Cong-Nhat Huynh. Gelatin Encapsulated Curcumin Nanoparticles Moderate Behavior of Human Primary Gingival Fibroblasts In Vitro. Journal of Nanomaterials. 2020; (9):1-11.

13. Ravinanthanan M, Hegde MN, Shetty V, Kumari S. Cytotoxicity Evaluation of Combination Irrigant Regimens with MTAD on Two Different Cell Lines. Contemp Clin Dent. 2018;9(2):255-259.

14. Collado-González, M.; Pecci-Lloret, M.R.; Tomás-Catalá, C.J.; García-Bernal, D.; Oñate-Sánchez, R.E.; Llena, C.; Forner, L.; Rosa, V.; Rodríguez-Lozano, F.J. Thermosetting glass ionomer cements promote variable biological responses of human dental pulp stem cells. Dent. Mater. 2018, 34, 932-943.

15. Celik N, Binnetoglu D, Ozakar Ilday N, Hacimuftuoglu A, Seven N. The cytotoxic and oxidative effects of restorative materials in cultured human gingival fibroblasts. Drug Chem Toxicol. 2019; 31:1-6.

16. Michel A, Erber R, Frese C, Gehrig H, Saure D, Mente J. In vitro evaluation of different dental materials used for the treatment of extensive cervical root defects using human periodontal cells. Clin Oral Investig. 2017;21(3):753-761.

17. Costa A.R , Banzi E.C.F , Puppin-Rontani R.M, Tipton DA, Correr-Sobrinho L, Garcia-Godoy F, Babu J.P. Longterm dental adhesive toxicity on human gingival fibroblasts and epithelial cells. Dental oral biology and craniofacial research. 2019; 2(3): 2-7.

18. Souza NJ, Justo GZ, Oliveira CR, Haun M, Bincoletto C. Cytotoxicity of materials used in perforation repair tested using the V79 fibroblast cell line and the granulocyte-macrophage progenitor cells. Int Endod J. 2006; 39(1):40-7.

19. Franz A, König F, Lucas T, Watts DC, Schedle A. Cytotoxic effects of dental bonding substances as a function of degree of conversion. Dent Mater. 2009; 25(2):232-9.

20. López-García S, Pecci-Lloret MP, Pecci-Lloret MR, Oñate-Sánchez RE, García-Bernal D, Castelo-Baz P, Rodríguez-Lozano FJ, Guerrero-Gironés J. In Vitro Evaluation of the Biological Effects of ACTIVA Kids BioACTIVE Restorative, Ionolux, and Riva Light Cure on Human Dental Pulp Stem Cells. Materials (Basel). 2019; 8;12(22):3694. 
21. Szep S, Kunkel A, Ronge K, Heidemann D. Cytotoxicity of modern dentin adhesives--in vitro testing on gingival fibroblasts. J Biomed Mater Res. 2002;63(1):53-60.

22. Kanjevac T, Milovanovic M, Volarevic V, Lukic ML, Arsenijevic N, Markovic D, Zdravkovic N, Tesic Z, Lukic A. Cytotoxic effects of glass ionomer cements on human dental pulp stem cells correlate with fluoride release. Med Chem. 2012; 8(1):40-5.

23. Shen C. Dental Cements. In: Anusavice KJ, editor. Phillips' Science of Dental Materials.11st ed. Missouri USA: Saunders Elsevier; 2007. Pp. 474.

24. Stanislawski L, Daniau X, Lauti A, Goldberg M. Factors responsible for pulp cell cytotoxicity induced by resinmodified glass ionomer cements. J Biomed Mater Res. 1999;48(3):277-88.

25. Sidhu SK, Schmalz G. The biocompatibility of glassionomer cement materials. A status report for the American Journal of Dentistry. Am J Dent. 2001;14(6):387-96.

26. Soheili ME, Golberg M, Stanislawski L. In vitro effects of ascorbate and Trolox on the biocompatibility of dental restorative materials. Biomater. 2003; 24:3-9.
27. Marcia Hiromi Tanaka, Alberto Camilo Alecio, Danilo Luiz Flumigna, José Eduardo de Oliviera, Elisa Maria Aparecida Giro. Inorganic elemental analysis and identification of residual monomers released from different glass ionomer cements in cell culture medium Rev Odontol UNESP. 2013; 42(4): 273-282

28. Chang YC, Chou MY. Cytotoxicity of fluoride on human pulp cell cultures in vitro. Oral Surg Oral Med Oral Pathol Oral Radiol Endod. 2001;91(2):230-4.

29. Theiszova M, Jantova S, Letasiova S, Palou M, Cipak L. Cytotoxicity of hydroxyapatite, fluorapatite and fluorhydroxyapatite: a comparative in vitro study. Neoplasma. 2008;55(4):312-6.

30. de Mendonça AA, Souza PP, Hebling J, Costa CA. Cytotoxic effects of hard-setting cements applied on the odontoblast cell line MDPC-23. Oral Surg Oral Med Oral Pathol Oral Radiol Endod. 2007;104 (4): 102-8.

31. Rodriguez IA, Ferrara CA, Campos-Sanchez F, Alaminos M, Echevarría JU, Campos A. An in vitro biocompatibility study of conventional and resin-modified glass ionomer cements. J Adhes Dent. 2013;15(6):541-6. 